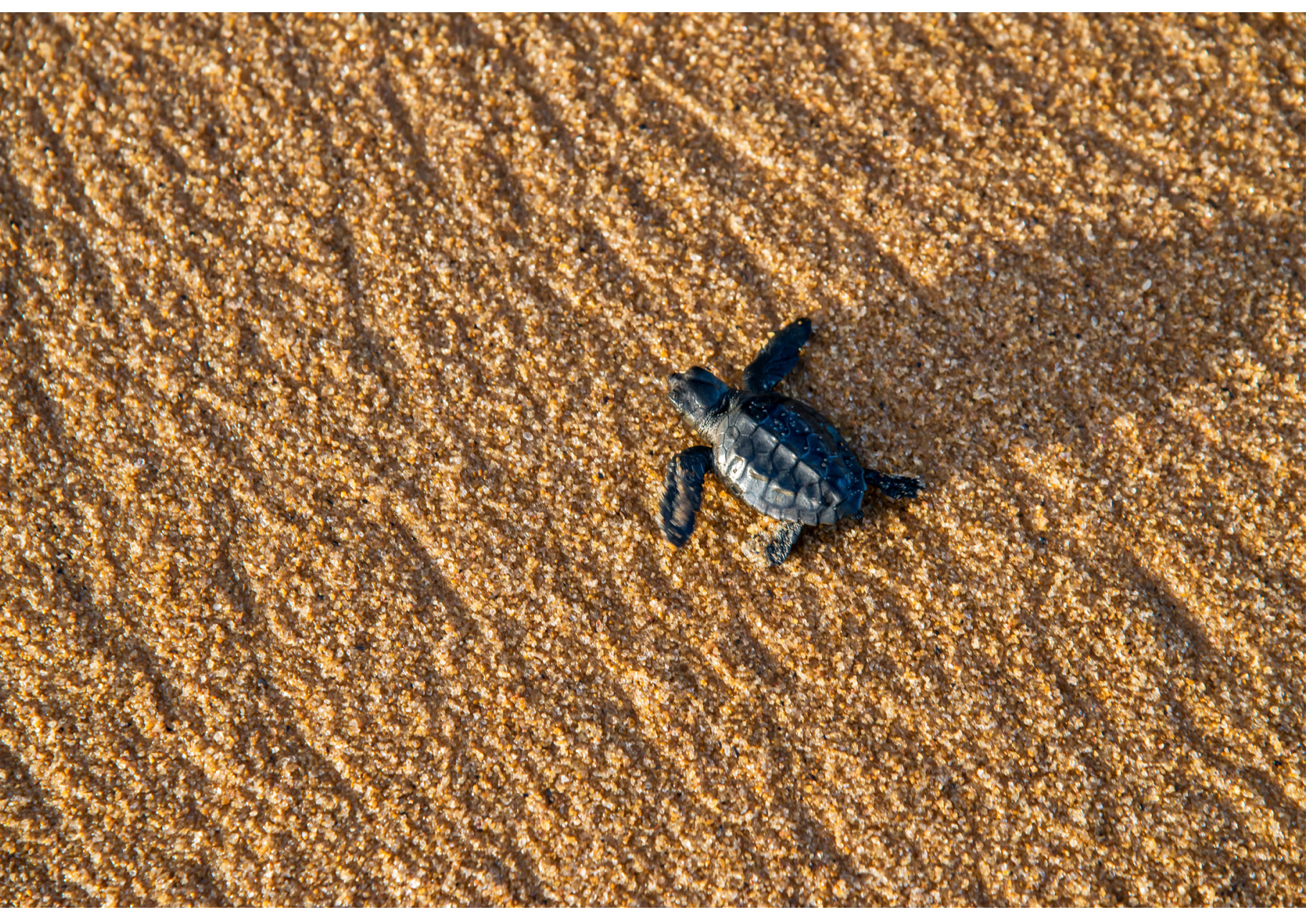




\section{A Extensão em Três Esferas: \\ Museu de Zoologia, Ensino e Comunidade}

Extension in Three Spheres: Museum of Zoology, Education and Community

\section{Resumo}

Museus são ferramentas de suma importância na formação educacional; são como portais para um mundo filosófico, que se torna fonte preciosa de conhecimento e descobertas. O objetivo do estudo foi ampliar e fortalecer as atividades científico-culturais por meio da divulgação do Museu de Zoologia Newton Baião de Azevedo da UEMG Carangola (MZNB). Para isso, a extensão se deu através de exposições itinerantes, eventos científicos e palestras em escolas de diferentes níveis de ensino. De acordo com os resultados, as informações foram disseminadas em todos os níveis pretendidos, com acentuado despertar de interesse. 0 público em questão foi além dos conteúdos presentes no estudo formal, que consequentemente se expandiu para a população de Carangola e região. Faz-se necessária uma revisão crítica sobre o uso de museus no ensino do Brasil, de modo a incluir e incorporar uma relação professores, museus e alunos.

Palavras-chave: Extensão; Educação Ambiental; Fauna e Conscientização.

Isteliene Lopes Leodoro Michel Barros Faria*

Universidade do Estado de Minas Gerais (UEMG) - Unidade Carangola *E-mail: michelfaria@yahoo.com.br 
Abstract

Museums are tools importance in educational formation, they are like portals to a philosophical world that becomes a precious source of knowledge and discoveries. The objective of the study was to expand and strengthen scientific-cultural activities through the dissemination of the Museum of Zoology Newton Baião de Azevedo the UEMG Carangola (MZNB). For this to the extent it was given through itinerant exhibitions, scientific events and lectures in schools of different levels of education. According to the results, the information was disseminated in all the target levels, with a marked arousal of interest. The public in question went beyond the contents present in the formal study, which consequently expanded to the population of Carangola and region.

It is necessary to critically review the use of museums in Brazilian education, in order to include and incorporate a relationship between teachers, museums and students. 


\section{INTRODUÇÃO}

O Museu de Zoologia Newton Baião de Azevedo (MZNB) possui um rico acervo biológico representado por espécies da Mata Atlântica na região de Carangola - MG. Este acervo torna-se ainda mais valioso pelo fato de a Mata Atlântica ser um bioma exclusivo do Brasil, representando um dos ecossistemas mais ricos em diversidade e endemismos de espécies animais, constituindo-se também em um dos mais ameaçados do planeta (CULLEN JR. et al., 2000). Isso reforça a necessidade de conservá-lo, enriquecê-lo, mantê-lo organizado e principalmente divulgá-lo em todas as esferas do ensino e na comunidade.

É fato que os museus têm possibilidades educativas nos âmbitos formal, não formal e informal do ensino, e dependem do uso que se faça dele por meio das atividades desenvolvidas junto ao público que os utilize, das condições da visita, dos conhecimentos prévios, dos interesses e dos objetivos, possibilitando que o museu se torne instrumento de aprendizagem (JUANOLA \& COLOMER, 2005). Acrescenta-se que as Coleções Científicas conservadas nos museus são importantes para o conhecimento da biodiversidade, por meio de pesquisas realizadas com o acervo, tais como estudos taxonômicos, ecológicos e biogeográficos (VIVO, 1996). A educação não-formal se insere no contexto do ensino-aprendizagem como uma forma de aplicação dos conhecimentos adquiridos no cotidiano, deixando ver aos alunos a importância do que aprendem no ambiente escolar e, ainda, tornando "as atividades mais atrativas, estimulando a curiosidade e a construção do conhecimento pelos próprios alunos” (OLIVEIRA et al., 2011). Partindo dessas considerações buscou-se como objetivo para este trabalho transmitir informações culturais e pedagógicas sobre animais, contribuindo assim com a formação do indivíduo no sentido de interagir com o outro em sociedade e com a natureza. Essa troca de saberes se deu entre o Museu de Zoologia e alunos de diferentes níveis de ensino, através do uso de seu acervo utilizado como método para a educação não-formal.

O objetivo do trabalho, como veremos a seguir, foi divulgar o acervo do Museu de Zoologia Newton Baião de Azevedo e a sua importância para o ensino, despertando o interesse e a conscientização da comunidade em geral e de alunos nos ensinos básico, fundamental, médio e superior das escolas públicas e particulares do município de Carangola - MG e região.

\section{METODOLOGIA}

\section{Áreas de Estudo}

O trabalho foi desenvolvido no MZNB da Universidade do Estado de Minas Gerais Unidade Carangola (UEMG Carangola). Para esse estudo foi disponibilizada a coleção de zoologia pertencente ao Museu, composta por representantes da fauna de peixes, anfíbios, répteis, aves e mamíferos. Estas coleções são abertas a visitações nos diferentes níveis de ensino (do básico ao superior) e atendem o município de Carangola e região, principalmente dos estados de Minas Gerais, Espírito Santo e Rio de Janeiro. 
O Museu está localizado no terceiro andar do Bloco "B" da Universidade, estruturado em uma sala grande dividida em três partes: (i) uma sala específica para a curadoria, (ii) uma sala para os alunos estagiários, (iii) e uma sala principal, onde ficam as coleções científicas e em exposição (Figura 1) (FARIA \& CASUTE, 2015). A equipe responsável pelas atividades do Museu, atualmente, consta de um curador, um biólogo técnico voluntário e alunos estagiários, bolsistas e não bolsistas.

O espaço fica aberto à visitação de segunda a sexta-feira das 13 às 18 horas, atendendo a comunidade de Carangola e região e o meio acadêmico, oferecendo atividades interativas para estudantes dos diferentes níveis de ensino, professores e pesquisadores. Alunos do curso de Ciências Biológicas desenvolvem a extensão no MZNB, ministrando palestras para esclarecimento de dúvidas empíricas e científicas, a fim de desmitificar fatos relacionados à fauna selvagem e esclarecer questões importantes e reflexões sobre a perda da biodiversidade regional. Abaixo, fotos do Museu.
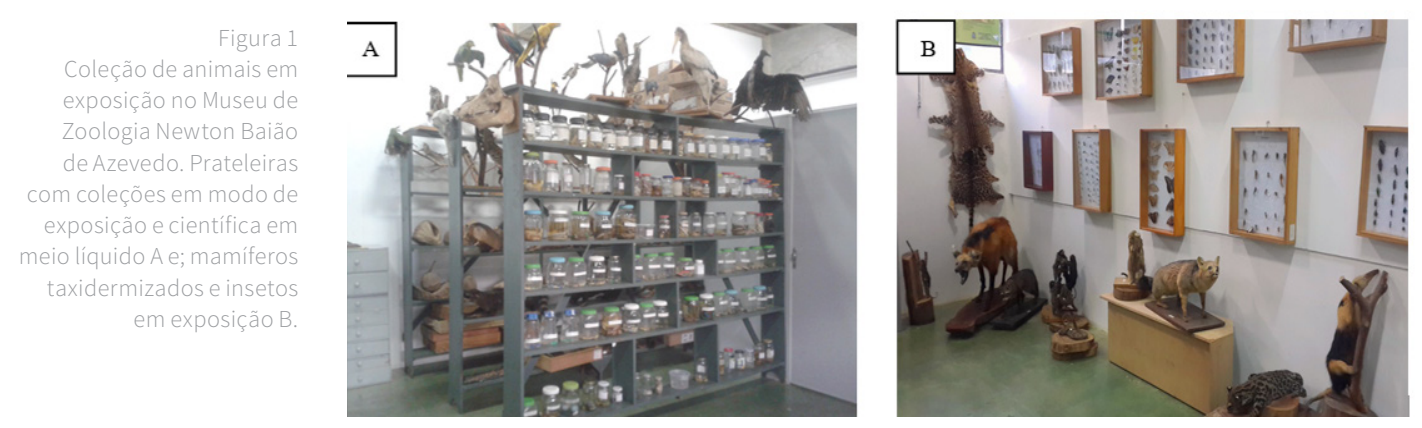

\section{Métodos Aplicados}

A coleta de dados foi obtida através de duas diferentes situações, i) visitas em escolas para convidar professores e alunos a conhecer o MZNB, ii) visitas recebidas no museu. As visitas foram pré-agendadas com dias e horários marcados no período de segunda-feira a sexta-feira das $13 \mathrm{~h} 00 \mathrm{~min}$ às $17 \mathrm{~h} 00 \mathrm{~min}$. Foram recebidas escolas dos ensinos iniciais, fundamental e médio de escolas públicas, particulares e municipais (figura 2). 

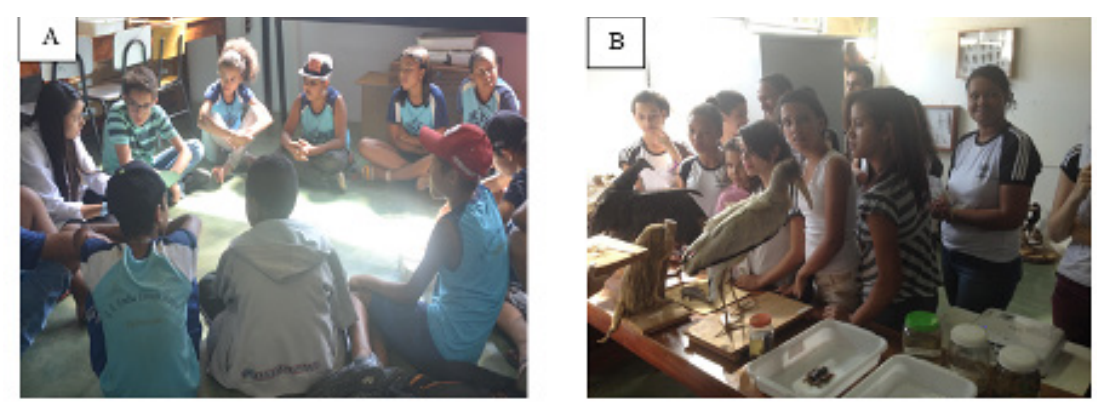

Figura 2

Visitas de alunos da rede públicas e particulares recebidas no Museu de Zoologia Newton Baião de Azevedo. A - Escola Estadual Emília Esteves Marques. B - Escola Estadual Jõao Belo de Oliveira. C - Escola Officina do Saber. D - Centro Educacional São José
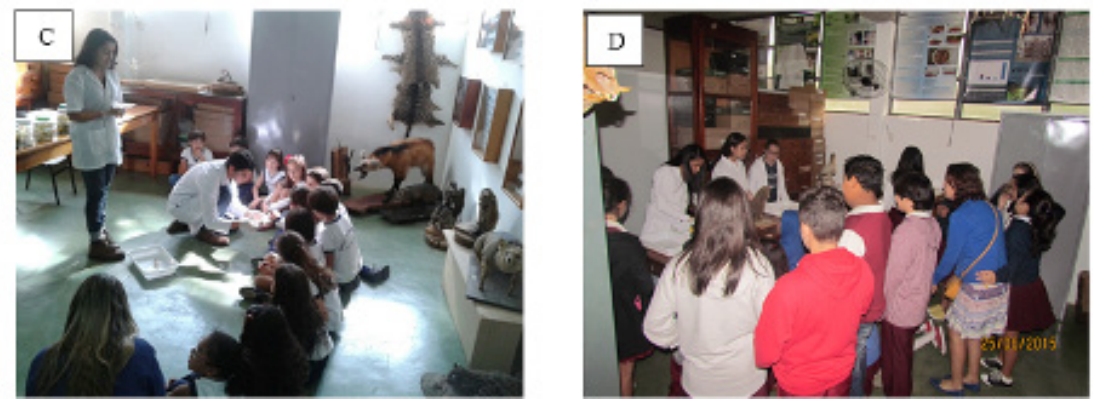

Foi disponibilizado um livro de assinaturas para o controle do número de visitantes para as escolas recebidas no acervo do MZNB (fiscalização formal) de assinaturas, considerando o registro voluntário. No livro constou nome, instituição/ cidade e data (Figura 4). No final de cada visita foram aplicados questionários (Anexo I). O período de coleta das informações se deu entre março de 2015 a fevereiro de 2016.
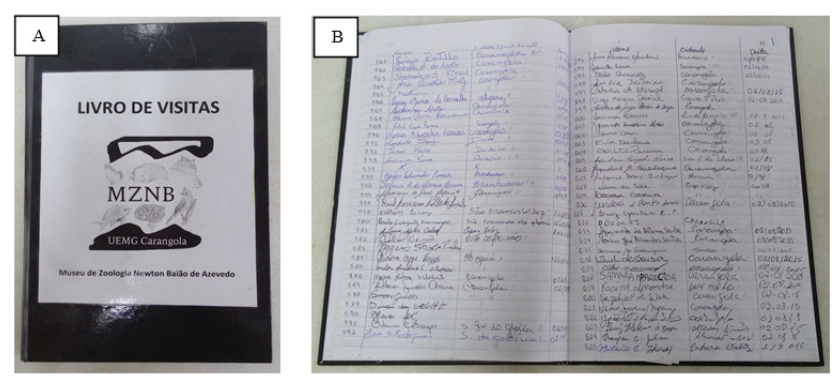

Figura 4

Livro de assinatura de visitação do Museu de Zoologia Newton Baião de Azevedo (A - indica capa do livro de assinatura de visitas e B páginas assinadas do livro)

Interpretação dos dados

Os dados foram organizados em tabelas do Office Excel 2013. O mesmo foi também utilizado para confecção de gráficos. As respostas obtidas dos visitantes através dos questionários aplicados foram separadas e interpretadas individualmente. 


\section{RESULTADOS}

A extensão do Museu nos ensinos básico, fundamental, médio e superior

Ao receber os visitantes das escolas, primeiramente as turmas foram divididas em grupos de aproximadamente 15 alunos. Posteriormente foram levadas para o museu acompanhado pelos estagiários, para a apresentação. Para maior entendimento dos alunos, todo o material de exposição foi disponibilizado. Foram recebidas dez escolas públicas e particulares do municipio de Carangola - MG e região, de diferentes níveis de escolaridade, que totalizaram aproximadamente 600 alunos. As escolas recebidas foram: Escola Estadual João Belo de Oliveira, Escola Estadual Melo Viana, Escola Estadual Dr. Jonas de Faria Castro, Escola Officina do Saber, Escola Portal da Educação, Escola Estadual Emília Esteves Marques, Escola Estadual Prof. Augusto Amarante, Escola Estadual Benedito Valadares e Universidade do Estado de Minas Gerais Unidade Carangola, pertecentes à cidade de Carangola - MG e o Centro Educacional São José da cidade Natividade - RJ (Figura 5).
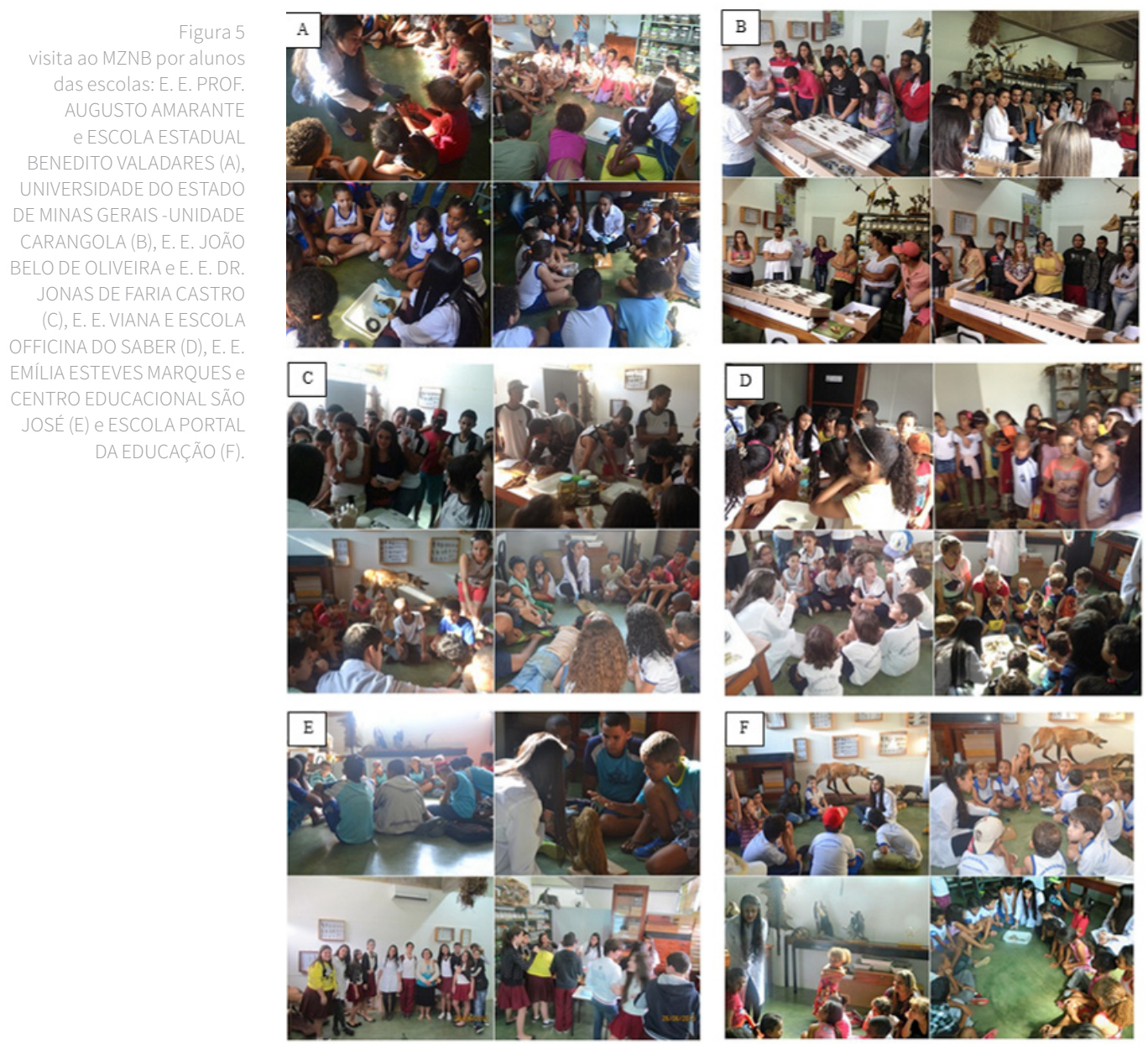
Das dez escolas recebidas, seis responderam ao questionário, totalizando um número de 234 alunos. Houve grande diferença no número de visitantes com relação aos níveis de ensino, sendo os básicos menos representativos (Figura 6A). Isso pode ser entendido por as turmas dos ensinos iniciais serem menos numerosas e também porque muitas não responderam ao questionário devido à faixa etária. A forma de avaliação desses alunos foi por meio de desenhos (Anexo II).

A idade entre os alunos analisados variou de 3 a 50 anos, sendo a faixa etária de 11 a 15 anos a mais representativa, isso porque é maior o número de estudantes nas turmas do ensino fundamental e médio. Nenhum questionário foi respondido por estudante até cinco anos (Figura 6B). Na pergunta sobre a definição do que é um museu zoologia (pergunta 1; anexo I), todas as respostas foram semelhantes e relacionadas à preservação, ao estudo e conservação dos animais. A pergunta 2 foi referente à visitação em outros museus, no qual a maioria dos visitantes respondeu que já foi a museus (Figura 6C), sendo os mais mencionados o Museu Municipal de Carangola-MG; Museu Nacional UFRJ; Museu de Zoologia da PUC. O Museu de Petrópolis e Museu de Curitiba foi mencionado uma única vez.

Ficou registrado que o município de Carangola não oferece grandes atrativos culturais aos moradores, como aponta a pergunta número três, sobre atividade de ida ao cinema, ao teatro, à praia, assistir a espetáculo musical/dança, visitar exposições/museus e/ou assistir telecomunicações. Como pode ser observado na Figura 6D, assistir televisão foi respondido pela maioria dos entrevistados. De forma contrária, respostas como ir ao teatro ou ao cinema foram minimamente representadas. Isso se justifica pela falta de atrativos e de opões oferecidos à maioria dos entrevistados, que são semelhantes nas duas respostas acima mencionadas. A localização geográfica da cidade oferece o litoral Capixaba como opção de praias e foi consideravelmente apontada como opção de distração (figura 6D).
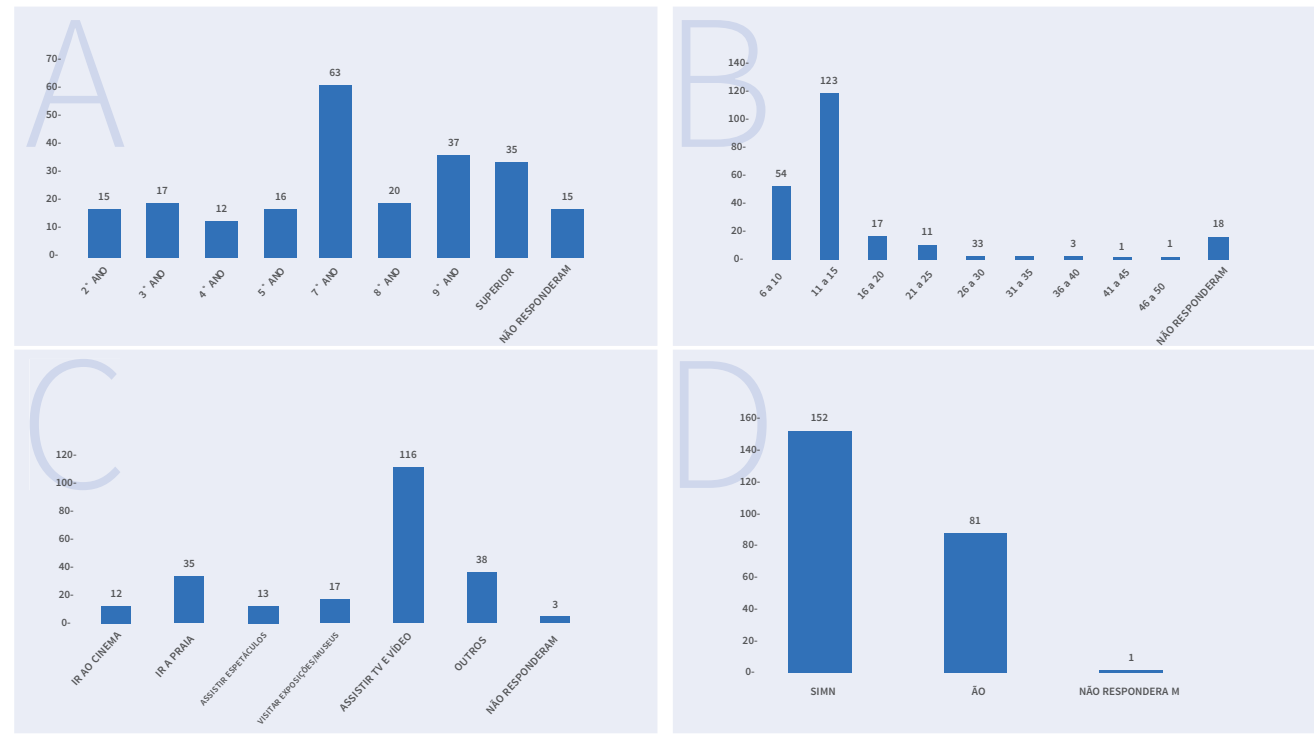

Figura 6

A) Representatividade do nível de escolaridade das escolas que visitaram o MZNB (eixo x). Número de acordo com os questionários respondidos (eixo y). B) Número da idade dos alunos que visitaram o MZNB (eixo x). Número de acordo com os questionários respondidos (eixo y). C) O número de entrevistados que já visitaram museus foi maior em 65\% das respostas (eixo $\mathrm{x}$ ). Número de acordo com os questionários respondidos (eixo y). D) Atrativos culturais pesquisados para os moradores de Carangola e região (eixo x). Número de acordo com os questionários respondidos (eixo y). 
Em relação aos objetos (animais) expostos que mais entusiasmaram os visitantes do museu (pergunta 4; Anexo I), foram apresentadas diversas respostas sendo a maioria relacionada às peças taxidermizadas e de maior tamanho como o lobo-guará (Chrysocyon brachyurus), a gato-do-mato-pequeno (Leopardus tigrinus) e a cascavel (Crotallus sp.). Peças em meio líquido, principalmente os répteis foram também muito mencionadas. A pergunta de número cinco buscou verificar se os visitantes tinham opinião sobre a importância e de como um museu de zoologia pode ajudar na conservação da natureza. A maioria dos visitantes respondeu que o museu é importante e suas justificativas podem ser resumidas como: o museu é importante no ensino e pode contribuir para a preservação da natureza, pois ajuda a entender a vida dos animais e sua relação com o homem. As respostas mecionadas com "não" ou seja, de que o museu de zoologia não ajudaria na conservação da natureza, foram justificadas pelo fato de o museu exibir animais mortos (Figura 07). Isso mostra que a comunidade de Carangola conhece pouco sobre a existência do MZNB e muito menos sobre sua interação ensino-comunidade.
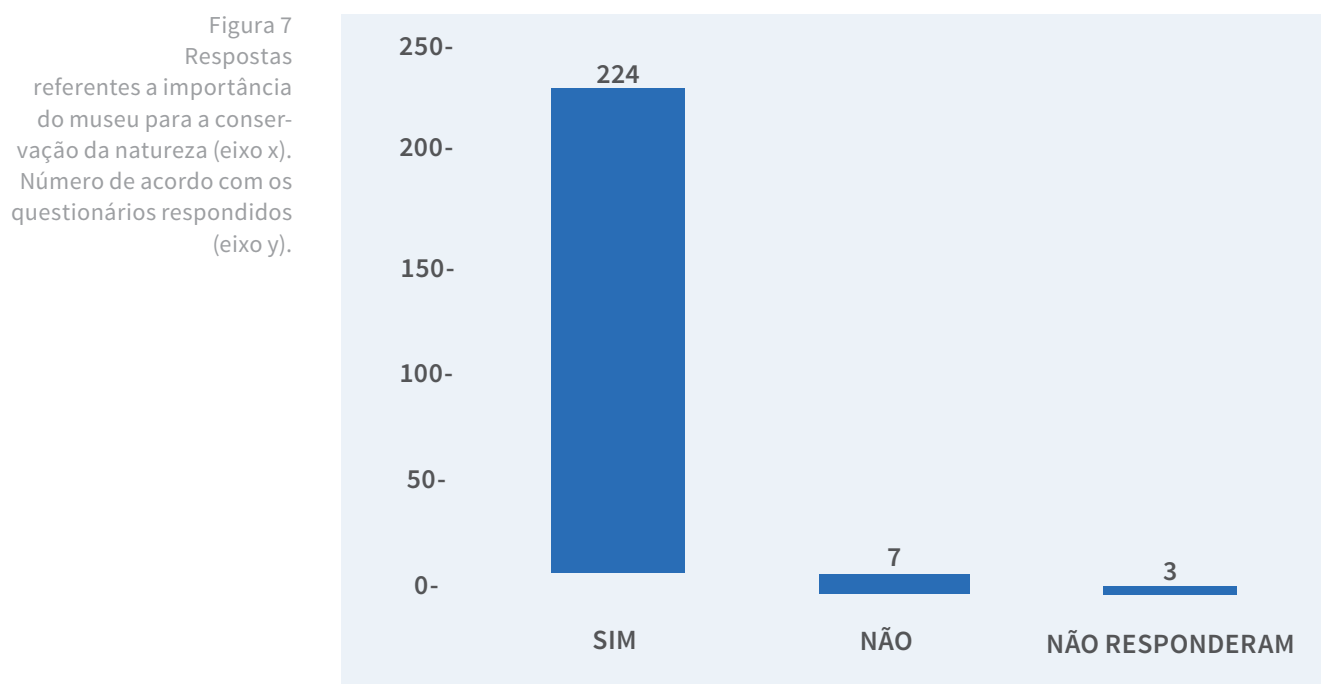

À pergunta de número 6 (Anexo I) -"Entre os animais da exposição que você já havia visto"- foram informados animais, como; papagaios, maritacas, urubu-de-cabeça-preta (Urubu-de-cabeça-preta), ouriço-cacheiro (Sphigurus vilosus), tatu - galinha (Dasypus novemcinctus), anfíbios (sapos, pererecas e rãs) e répteis (cobras), pois esses animais são comumente encontrados em áreas peridomiciliares. No questionamento aos visitantes sobre o que deveria mudar no museu (pergunta 7, Anexo I), as respostas foram bem semelhantes, e numeradas na seguinte ordem: falta de espaço e poucas peças ilustrativas, justificadas por atrapalhar as dinâmicas realizadas (espaço), e mais exemplares da nossa fauna para esclarecer ou atender melhor as dúvidas sobre interação ecológica, ameaça e interação fauna-homem. 
Indagado (pergunta 8, Anexo I) sobre o que os visitantes gostariam de ver no museu, dentre as respostas destacaram-se: peças históricas, animais exóticos, esqueleto de dinossauro, onça pintada, leão e jacaré. É possível que essas respostas se deram por influência da telecomunicação e da internet, como desenhos de animais que retratam, muitas das vezes, uma fauna exótica e oferecem informações sobre grandes predadores que despertam maior interesse.

As respostas analisadas a partir das perguntas 9, 10 e 11 relacionaram-se a questões sobre a mensagem que o museu passou e a orientações para se cuidar dos animais; o que os visitantes aprenderam no MZNB e se houve interesse em conhecer outros museus. Pelas respostas apresentadas observou-se grande preocupação com o cuidado para com os animais, a importância da preservação da natureza, com um trabalho organizado, os mitos que foram quebrados com as visitas e que a atividade no MZNB despertou o interesse em conhecer outros museus. Ficou evidenciado que os visitantes tinham opiniões fortemente criadas de forma empírica e que precisavam ser discutidas e revistas como, por exemplo, a de que maioria dos morcegos que se alimentam de frutos e insetos e jamais irá sugar sangue humano; que porcos espinhos não lançam seus espinhos contra as pessoas e que os sapos são inofensivos e que não devem ser tocados.

Por fim foi perguntado sobre o grau de satisfação causado pela visita, em que 60\% dos visitantes responderam estar muito satisfeitos e 34 satisfeitos (Figura 8). Verificou-se que a possibilidade de se criar conexões entre o que os alunos observam, com os ambientes do cotidiano ou aspectos já aprendidos na própria escola e os conhecimentos científicos, surge durante o planejamento das ações, mas deve ser enfaticamente estimulada durante a visita para aumentar o potencial do aprendizado e despertar o interesse de voltar ao MZNB, bem como trazer pessoas e conhecer outros museus de zoologia.

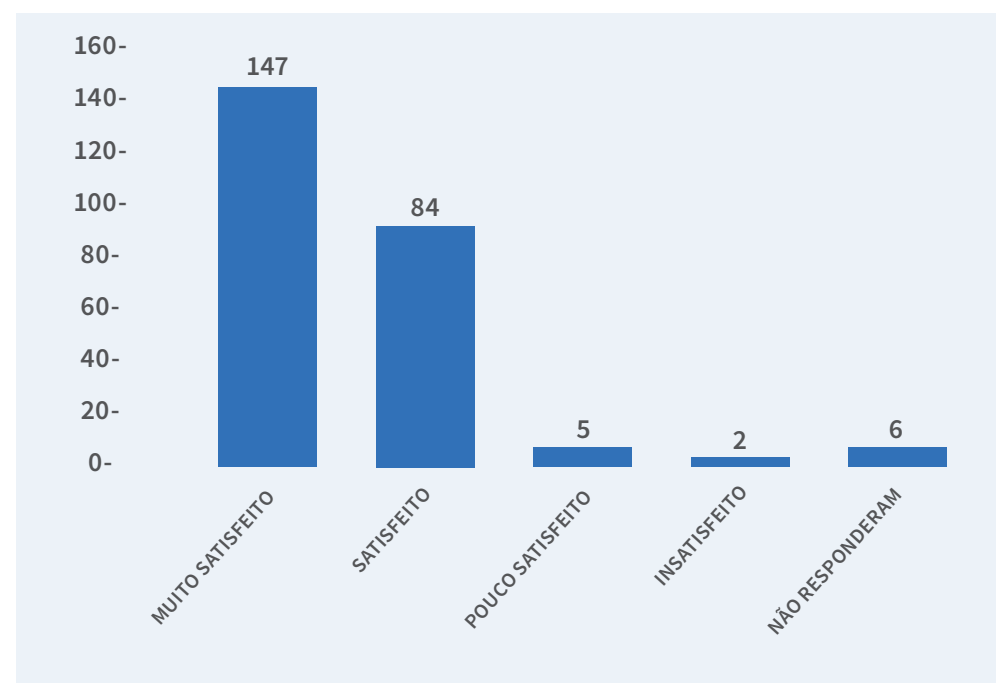

Figura 8

Mostra o

grau de satisfação dos visitantes após sua visita (eixo x). Número de acordo com os questionários respondidos (eixo y). 


\section{DISCUSSÃO/CONCLUSÃO}

É perceptível que os números de alunos em sala de aula são diferentes entre os níveis de ensino, e também entre escolas públicas e privadas (dados aqui não ilustrados). Não é novidade afirmar que as turmas escolares brasileiras possuem mais alunos do que deveriam. A Lei de Diretrizes e Bases da Educação (Brasil, 1996) estabelece que é dever do estado manter a educação escolar pública garantindo padrões mínimos para a qualidade de ensino, definidos como a variedade e quantidade mínimas, por aluno, de insumos indispensáveis ao desenvolvimento do processo de ensino (Brasil, 1996). Acontece que, sem uma legislação nacional para definir numericamente o mínimo e máximo de alunos em sala de aula por nível de ensino, alguns Estados acabam por adotar regras próprias ou acordos com a superintendência para este controle. Outros até mesmo deixam os colégios decidirem estas questões.

Nossos dados não nos permitem fazer afirmação sobre a relação número de alunos-qualidade de ensino. Alguns pedagogos ressaltam que diminuir o número de alunos por professor não é suficiente para garantir a aprendizagem de todos: é preciso mudar o compromisso com a educação (Borges, 2013).

De acordo com o mais recente Censo da Educação Básica do Brasil (Brasil, 2014), mais de 8,5 milhões de alunos estão atrasados na escola em aproximadamente dois anos. Os dados do MEC também mostram que é maior o número de estudantes atrasados no ensino médio em relação ao ensino fundamental 6,1 e 2,4 milhões de alunos, respectivamente (Brasil, 2014).

A interação escolas e Museus se faz também importante para minimizar o número egresso, principalmente nos níveis finais. De acordo com o senso da Educação Básica de 2013 (Brasil, 2014) realizado em regime de colaboração com as secretarias estaduais (27) e municipais (5.570) de educação, com a participação de todas as escolas do País, o número de estudantes matriculados entre os anos de 2007 a 2013 diminuiu nos dois anos do Ensino Fundamental (iniciais e finais) e no Ensino Médio.

O decréscimo observado no quantitativo de matrículas da educação básica decorre, principalmente, da acomodação do sistema educacional, em especial na modalidade regular do Ensino Fundamental, com histórico de retenção e, consequentemente, altos índices de distorção idade-série. Ao mesmo tempo, vale destacar a ampliação da oferta da educação infantil, em especial na creche, voltada para o atendimento das crianças com até 3 anos de idade, que apresentou crescimento da ordem de 7,5\% (Instituto Nacional de Estudos e Pesquisas Educacionais Anísio Teixeira, 2013). Outro aspecto que tem impacto na distribuição e no contingente de alunos na educação básica é o comportamento dos indicadores de rendimento escolar. Com mais alunos sendo aprovados e promovidos às séries subsequentes, aumenta o número de habilitados a ingressar nas próximas etapas de escolarização. Os especialistas chamam esse movimento de fluxo escolar (Instituto Nacional de Estudos e Pesquisas Educacionais Anísio Teixeira, 2013). 
Como vimos, as aulas em espaços não formais de educação podem contribuir para motivar a aprendizagem e em consequência a diminuir a evasão escolar. Nesse sentido, espera-se que a divulgação do MZNB desperte entusiasmo por novas visitas às coleções e a sua aplicação ao ensino de ciências. Outro ponto observado com a oferta das atividades do projeto é que a comunidade deseja que o turismo da região movimente a economia e respeite os patrimônios que a cidade possui. Ficou evidenciado a necessidade de se promover um serviço de qualidade, que incentive o turista a permanecer na cidade por mais tempo, consumindo produtos e serviços que o faça sentir o desejo de retornar (Instituto Brasileiro de Museus, 2014).

Entre as questões apresentadas nos questionários sublinha-se respostas como estudar, visitar reservas ecológicas próximas e a prática de esportes como atividades de lazer e de interação da comunidade. De acordo com Souza (2002) o problema urbano relacionado à falta de interação entre cultura e acesso civil faz parte do cotidiano de toda cidade brasileira, independentemente de seu tamanho e localização.

O fato é que o município de Carangola possui espaço para atividades culturais e para alojar ambientes para distintos atrativos, mas encontra-se em ruim estado de conservação, necessitando de restauração. A falta de gestão, entendida como "crise" dos espaços de memória, implica um processo de reflexão sobre a informação histórica da cidade, que sofre ameaças em meio ao caos, carecendo de restauração e preservação, em virtude dos interesses particulares e da expansão urbana desordenada (Silva et al. 2011). De acordo com Almeida (1995), estudos sobre a interação do público são ferramentas importantes para a melhoria das exposições. Museus se transformaram em redutos ecológicos importantes para as inúmeras espécies de animais, podendo ser consideradas como ecossistemas completos (Nunes, 2011). Mortimer (1995) afirma que há pessoas que conseguem compreender as ideias científicas, mas que nunca se desfazem de seus conhecimentos prévios, construídos a partir de suas vivências, cujas experiências podem ser somadas aos conhecimentos oferecidos na educação escolar.

Os dados mostram a questão educacional do MZNB para a UEMG e a cidade de Carangola, como unidade com potencial de informações que possibilita atingir todos os níveis de ensino. Através da divulgação do MZNB houve o despertar de interesse dos visitantes em conhecer outros centros culturais, o que nos leva a concluir que se faz necessária e urgente uma revisão crítica sobre o uso de museus no ensino do Brasil, de modo a se incluir e incorporar uma interação entre professores, museus e alunos.

\section{REFERÊNCIAS}

[1] Almeida, A.m. A Relação do Público com o Museu do Instituto Butantã: análise da exposição Na Natureza não Existem Vilões. Dissertação de Mestrado, ECA, São Paulo. 1995.

[2] Borges, P. Limite de alunos por turma depende de bom senso das escolas. Brasília 01 de fevereiro de 2013. Disponivel em: <http://ultimosegundo.ig.com.br/educacao/2013-02-01/limite-de-alunos-por-turma-depende-de- 
-bom-senso-das-escolas.html> Acesso em: 07 nov. 2015, 17:40:12

[3] Brasil. Lei de Diretrizes e Bases da Educação Nacional. Senado Federal. Senador Ramez Tebet. Lei no 9.394, de 20 dezembro de 1996.

[4] Brasil. Censo da Educação Básica do Brasil. Ministério da Educação. 2014. Disponível em: http://download.inep. gov.br/educacao_basica/censo_escolar/apresentacao/2014/apresentacao_coletiva_censo_edu_basica_022014 pdf Acesso em: 07 de novembro de 2015.

[5] Cullen, J.r.l.; Bodmer, R.e.; Padua, C.v. Effects of hunting in habitat fragments of the Atlantic forest, Brazil. Biological Conservation, Liverpool, 95: 49-56. 2000.

[6] Faria, M.b.; Souza, G.c. Popularização da ciência através do Museu de Zoologia Newton Baião de Azevedo: conservação da fauna. Revista Científica Semana Acadêmica, v. 000067, p. 1. 2015.

[7] Instituto Brasileiro De Museus. Museu e Turismo: Estratégias de Cooperação - Brasília, DF : Ibram, 2014. 80p. : Il. ; 23 Cm Isbn 978-85-63078-30-8 1. Museus. 2. Turismo. I. Instituto Brasileiro de Museus.

[8] Instituto Nacional De Estudos E Pesquisas Educacionais Anísio Teixeira. Censo Escolar da Educação Básica: resumo técnico / Instituto Nacional de Estudos e Pesquisas Educacionais Anísio Teixeira. Brasília : O Instituto, 2014. 39 p.: tab. ISBN 978-85-7863-033-1. 2013.

[9] Juanola, R.; Colomer, A. Museus Y Educadores: Perspetivas Y Retos de Futuro. In: La Mirada Inquieta: Educación Artística Y Museos. Editado por Ricard Huerta, e Romà de La Calle, 21-40. Valéncia: Universitat de València. 2005. [10] Mortimer, E.f. Conceptual Change or Conceptual Profile Change? Science and Education, 4, 267-285. 1995. NUNES, M. Fauna Urbana - a vida selvagem à nossa porta. Disponível em: Acesso em: 20 nov. 2012.NUNES, V. F. P. Pombos Urbanos - O Desafio de Controle em Áreas Urbanas. Anais da XII Reunião Itinerante de Fitossanidade do Instituto Biológico - Pragas Agroindustriais. 2011.

[11] Oliveira, M. P. C.; Rodarte, R. R. P.; Feio, R. N. Desenvolvimento de Métodos Interativos no Museu de Zoologia João Moojen - UFV, Mg. Revista Diálogos, V. 12, P. 57-62.

[12] Silva, G.p.; Falcão, M.t.; Barbosa, M.a.f. 2011. O Caso e o Descaso do Patrimônio Cultural da Cidade de Boa Vista-RR. Cultura, Ano 05. n० 02. 2011.

[13] Souza, M. L. De. Mudar a Cidade: Uma Introdução Crítica ao Planejamento e à Gestão Urbanos. Rio de Janeiro: Bertrand Brasil. 2002.

[14] Vivo, M. How many species of mammals are there in Brazil? Taxonomic practice and diversity evaluation. In: BICUDO, C.E. \& MENEZES, N.A. (ed.), Biodiversity in Brazil. A first approach. Proceedings of the workshop "Methods for the assessment of the biodiversity in plants and animals", Campos do Jordão. 1996. 


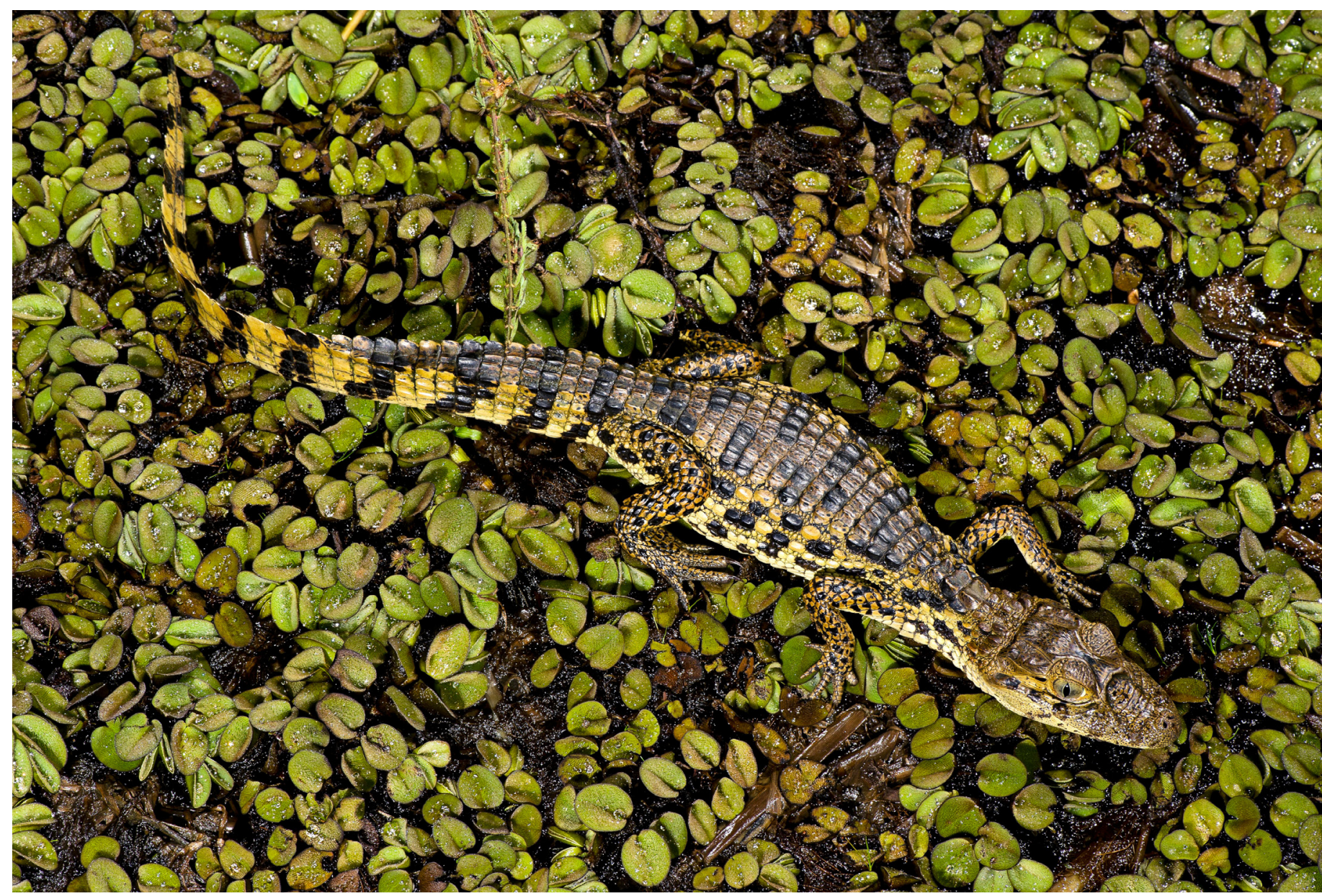

